\title{
Urban hypothermia: Preferred temperature and thermal perception in old age
}

\author{
K J COLLINS, A N EXTON-SMITH, CAROLINE DORÉ
}

\begin{abstract}
A study of 17 elderly men and 13 young adults of similar body build and wearing equivalent clothing insulation $(0.8$ clo) showed that when given control over their environment the elderly preferred the same mean comfort temperature $\left(22-23^{\circ} \mathrm{C}\right)$ but manipulated ambient temperature much less precisely than the young. Slow adjustment of ambient temperature was related in some cases to a higher temperature-discrimination threshold.

These findings suggest that both physiological and behavioural changes contribute to the increased vulnerability of old people in cold conditions.
\end{abstract}

\section{Introduction}

Of the many factors contributing to hypothermia in old people, two appear to have physiological importance. One is the agerelated decline in the efficiency of cold-defence mechanisms ${ }^{1-3}$ and the other the reduced ability to detect temperature change. ${ }^{2-4}$ Studies of thermal-comfort requirements of healthy elderly people and young adults suggest, however, that the neutral environmental temperature for comfort alters little with age. ${ }^{5-8}$ Since it is important to determine optimum ambient temperatures in the homes of elderly people, we have investigated how temperature preferences are made. The study used a remote-control technique ${ }^{9}$ in a rapidly responding temperature-controlled room in which each person could select his own preferred temperature. Simultaneously we investigated the ability to discriminate temperature differences.

Department of Geriatric Medicine, School of Medicine, University College London, St Pancras Hospital, London NW1 OPE

$\mathrm{K} J$ COLLINS, $M B$, DPHIL, member of MRC scientific staff and honorary senior lecturer in geriatric medicine

A N EXTON-SMITH, MD, FRCP, professor of geriatric medicine

Division of Computing and Statistics, Clinical Research Centre, Harrow, Middlesex HA1 3UJ

CAROLINE DORE, BSC, member of MRC scientific staff

\section{Subjects and methods}

Seventeen men aged 70 years and over were selected from residents living in their own homes in or near Chester. Ten (group 1) were in good health and seven (group 2) had cardiovascular or metabolic disorders that were medically well controlled-namely, hypertension (one), cerebrovascular accident in 1970 (two), peripheral vascular disease (one), left bundle-branch block with a pacemaker fitted in 1974 (one), ischaemic heart disease (one), and diabetes mellitus (one). The total sample was regarded as a representative cross-section of the mobile elderly population in the 70-80-year age range. They were drawn from a wide variety of social backgrounds and had preretirement occupations ranging from agricultural labourer to city treasurer. Thirteen men aged 18-39 years were also recruited, mostly from an employment agency. Their occupations ranged from scientist to part-time doorman. The purpose and procedure of the experiment were explained and a written form of consent signed by all subjects. The experiments were conducted with the customary ethical safeguards.

The controlled-environment room at the Electricity Council Research Centre, Capenhurst, may be heated and cooled rapidly by air from a conditioning system that is circulated through the permeable floor and extracted through perforated ceiling tiles. In this study air speed was less than $0.1 \mathrm{~m} / \mathrm{s}$. The walls are screened by curtaining, which ensures that mean radiant temperature changes with air temperature. Air temperature was measured at table height $(0.8 \mathrm{~m})$, and dry-bulb and wet-bulb temperatures at ceiling height $(2 \mathrm{~m})$. These temperatures, together with inlet-air temperature, were recorded continuously on a multipoint chart recorder (see figure). A two-position switch labelled "warmer" and "cooler," which could be operated at table height, enabled the subject to control the temperature of the room at will and change the air temperature at $0 \cdot 25^{\circ} \mathrm{C} / \mathrm{min}$.

On arrival at the research centre, the subject entered the temperature-controlled room and sat at a table in the middle; he remained there alone for three hours but could communicate audiovisually with the observer. Both elderly and young subjects wore clothing providing about 0.8 clo. (The clo is a unit of insulation defined as $1.0 \mathrm{clo}=R_{\mathrm{cl}} \times 0.18$, where $R_{\mathrm{cl}}$ is total heat-transfer resistance $\left({ }^{\circ} \mathrm{C} /\left(\mathrm{kcal} / \mathrm{h} / \mathrm{m}^{2}\right)\right)$ from skin to the outer clothed surface ${ }^{10}$; a typical business suit provides about $1 \mathrm{clo}^{6}$ )

After 30 minutes' equilibration at $19^{\circ} \mathrm{C}$ the control system was switched to "manual" and the subject instructed to control the temperature for two and a half hours, keeping as near as possible to his ideal. Since there was no neutral position, the subject had to make repeated evaluations of the ambient temperature and operate the switch to produce a "hunting" pattern (figure). The control switch was set in the cooling position at the beginning of each experiment and 
the subjects reminded about its operation and purpose every 15 minutes. Body temperatures (measured with oral, aural, and skin thermistors) were logged automatically at 15 -minute intervals and comfort votes (Bedford scale) ${ }^{11}$ half-hourly throughout. The sevenpoint Bedford scale of thermal comfort was applied as follows: +3 much too warm; +2 too warm; +1 comfortably warm; 0 comfortable (neutral temperature); -1 comfortably cool; -2 too cool; -3 much too cool. In the last 15 minutes digital thermal discrimination was tested in the cool $\left(24-26^{\circ} \mathrm{C}\right)$ and warm $\left(34-36^{\circ} \mathrm{C}\right)$ ranges, as described. ${ }^{34}$ Skinfold thickness (biceps and triceps), height, and weight, were also measured.

A $\chi^{2}$ test was used to compare the homogeneity of variance between the three groups and a one-way analysis of variance made for all variables to compare the three groups. Each pair of group means was then compared using $t$ tests. Any distribution of variables found to be skewed was corrected by log transformation. When the overall $\mathrm{F}$ ratio from the anova (analysis of variance) comparing all three groups was not significant, differences between the group means were also considered to be non-significant.

\section{Results}

Despite the difference in ages there were no significant differences in anthropometric characteristics between the groups (table I). Deep body (oral and aural) temperatures were similar at the end of the three-hour session, but mean trunk, foot, and hand skin temperatures were slightly lower in the older groups, especially group 2 (table II).

Components of the individual ambient temperature control curves were analysed as (1) maximum range-that is, temperature difference between maximum and minimum ambient temperature recorded at table height; (2) final range-temperature difference between final maximum and final minimum temperatures; (3) frequency of temperature change-total number of switch operations during remote-control period; and (4) preferred temperature-midpoint of final maximum and minimum temperatures. The patterns of ambient temperature control by the young subjects all closely resembled the damped-oscillation response described for young adults, ${ }^{9}$ but many of the elderly displayed poor control of the ambient temperature (figure). The mean maximum and final ranges of temperature were significantly greater and the frequency of temperature change less in groups 1 and 2 than in the young (table II). Nevertheless, despite the differences in temperature range, the mean preferred temperatures were not significantly different $\left(23.0 \pm 2 \cdot 3^{\circ} \mathrm{C}\right.$ in group 1 compared with $22 \cdot 7 \pm 1 \cdot 2^{\circ} \mathrm{C}$ in the young). The lower mean preferred

TABLE I-Physical characteristics of elderly and young adult subjects. Results expressed as means $\pm S D$

\begin{tabular}{|c|c|c|c|c|}
\hline & & \multirow{2}{*}{$\begin{array}{c}\text { Young } \\
(n=13)\end{array}$} & \multicolumn{2}{|c|}{ Elderly } \\
\hline & & & $\begin{array}{l}\text { Group } 1 \\
(n=10)\end{array}$ & $\underset{(n=7)}{\text { Group } 2}$ \\
\hline 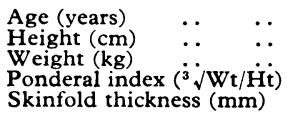 & $\begin{array}{l}\because \\
\because \\
\because \\
\because\end{array}$ & $\begin{array}{l}26 \cdot 8 \pm 7 \cdot 0 \\
176 \pm 5 \\
73 \cdot 2 \pm 8 \cdot 5 \\
2 \cdot 37 \pm 0 \cdot 10 \\
7 \cdot 8 \pm 3 \cdot 1\end{array}$ & $\begin{array}{l}74 \cdot 6 \pm 2 \cdot 8 \\
175 \pm 4 \\
72 \cdot 7 \pm 9 \cdot 8 \\
2 \cdot 38 \pm 0 \cdot 08 \\
6 \cdot 7 \pm 2 \cdot 1\end{array}$ & $\begin{aligned} 73 \cdot 0 & \pm 2 \cdot 5 \\
175 & \pm 6 \\
74 \cdot 9 & \pm 7 \cdot 3 \\
2 \cdot 38 & \pm 0 \cdot 10 \\
6 \cdot 3 & \pm 0.9\end{aligned}$ \\
\hline
\end{tabular}

temperature in group $2\left(20 \cdot 8 \pm 2 \cdot 3^{\circ} \mathrm{C}\right)$ was almost entirely accounted for by the diabetic patient, who had a distinct preference for low ambient temperatures (preferred temperature $15 \cdot 7^{\circ} \mathrm{C}$ ). The mean subjective comfort rating for all three groups was in the thermalcomfort zone, which accorded with our aim to maintain the room at optimum comfort.
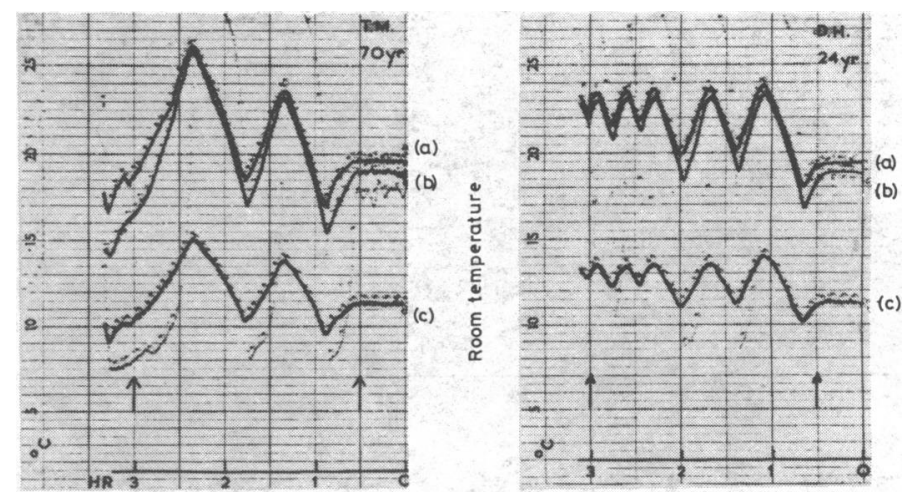

Room temperature controlled by elderly subject (man aged 70 ; left) and young adult (man aged 24 ; right). Room temperature maintained at $19^{\circ} \mathrm{C}$ for 30 minutes before remote-control period (time scale from right to left). Air temperature measured at $2 \mathrm{~m}(a)$ and at table height (b); wet-bulb temperature $(c)$.

Although a negative correlation exists between hand temperature and digital temperature discrimination, ${ }^{5}$ the slightly lower mean skin and hand temperatures in our elderly subjects did not completely account for the age-related difference in temperature discrimination shown in table II. Differences in discrimination were found between some elderly and young subjects with the same hand-skin temperature. Of the five poor temperature discriminators (discrimination exceeding $2^{\circ} \mathrm{C}$ ) in the elderly sample, only one (with peripheral vascular disease) was in group 2; hence a different subdivision of the elderly was made on the basis of good $\left(\leqslant 2^{\circ} \mathrm{C}\right)$ or poor $\left(>2^{\circ} \mathrm{C}\right)$ temperature discrimination (table III). The poor discriminators showed little difference in preferred temperature and comfort rating, but control of ambient temperature was impaired, with the maximum and final ranges of control greater and the frequency of temperature changes less than for the other elderly and young subjects. One-way analysis of variance showed significant differences in ambient temperature control respectively between the young adults, elderly with good discrimination, and elderly with poor discrimination (table III).

\section{Discussion}

Investigations on sedentary people clothed to provide 1.0 clo in controlled environments of $12-24^{\circ} \mathrm{C}$ disclosed a preferred temperature of $21.1^{\circ} \mathrm{C}$ for both elderly and young subjects. $^{35}$ About a quarter of the elderly subjects showed very poor temperature discrimination, while they also reported less

TABLE II-Body temperatures after three hours, temperature discrimination, and ambient temperature control in young adult and elderly subjects. Results expressed as means $\pm S D$

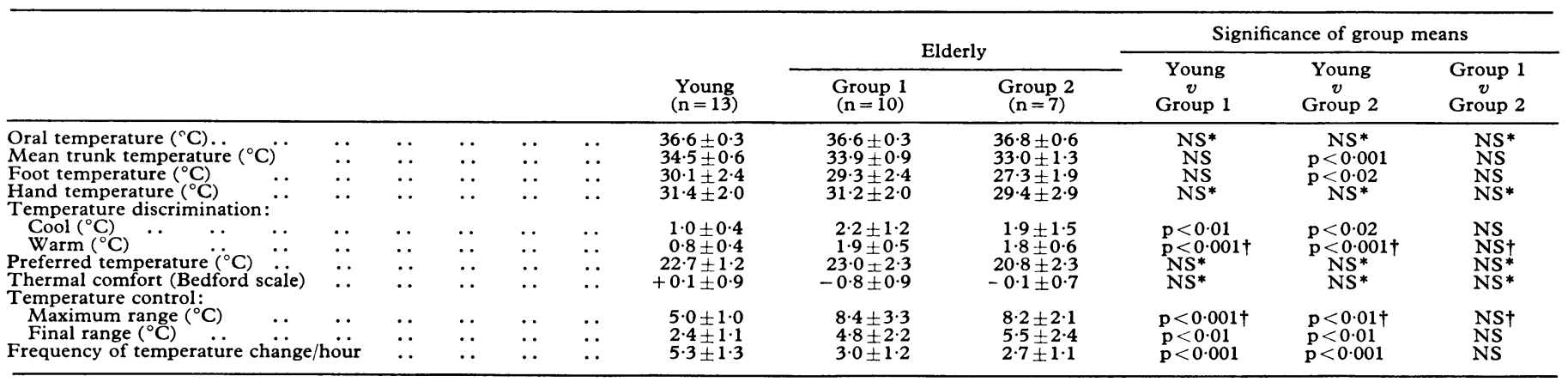




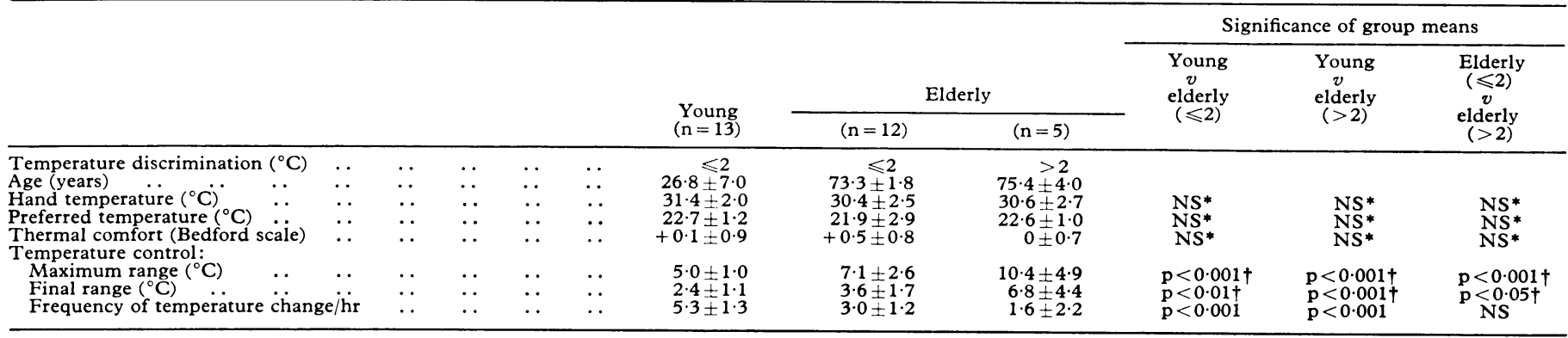

*Group comparison $F$ ratio not significant.

†Log-transformed data.

discomfort in the cold environments. Similarly, five of our 17 elderly subjects who were found to have poor temperature discrimination showed poor control of ambient temperature. Hence many old people apparently perceive peripheral temperature changes less accurately than the young, and some are particularly poor discriminators. Alternatively, the elderly may be less confident in reporting temperature differences rather than less able to detect them. This may be tested by applying the principles of signal-detection theory, ${ }^{12}$ though we did not do this. In experiments on a similar group of elderly and young subjects, ${ }^{3}$ however, using repeated "signal," "no-signal" tests, we concluded that there were no significant differences in the criteria on which the elderly and young based their decisions.

The method of determining preferred ambient temperature by individual self-selection of air temperature confirmed findings in static environments that the preferred temperature for most healthy elderly subjects is the same as that for young people. Our experiments also show that when given control over their environment the means of attaining preferred temperature by the elderly is less precise than by young people. This is apparently related to a deterioration with age in the ability to discriminate temperature differences. The combined effect of poor temperature discrimination and lack of precision in adjusting the thermal environment suggests that both physiological and behavioural factors contribute to the increased vulnerability of old people in cold conditions.

We thank the Electricity Council Research Centre for allowing us to use the controlled-temperature room at Capenhurst, and Drs D A McIntyre and J Charles-Jones for help during the study.

\section{References}

${ }^{1}$ Fox RH, Woodward PM, Exton-Smith AN, Green MF, Donnison DV, Wicks MH. Body temperatures in the elderly: a national study of physiological, social and environmental conditions. $B r$ Med $\mathcal{f} 1973$; i:200-6.

${ }^{2}$ Collins KJ, Doré C, Exton-Smith AN, Fox RH, MacDonald IC, Woodward PM. Accidental hypothermia and impaired temperature homoeostasis in the elderly. Br Med F 1977; $\mathrm{i}: 353-6$.

${ }^{3}$ Collins KJ, Exton-Smith AN. Urban hypothermia: thermoregulation, thermal perception and thermal comfort in the elderly. In: Adam JM, ed. Disasters caused by cold. Aberdeen:Aberdeen University Press (in press).

${ }^{4}$ Cowburn EJ, Fox RH. A technique for studying thermal perception. f Physiol (Lond) 1974;239:77-8P.

${ }^{5}$ Collins KJ. Hypothermia and thermal responsiveness in the elderly. In: Fanger PO, Valbjørn $\mathrm{O}$, eds. Indoor climate. Copenhagen:Danish Building Research Institute, 1979:821-33.

6 Fanger PO. Thermal comfort. New York and London:McGraw-Hill, 1972:73-86.

${ }^{7}$ Rohles FH, Johnson MA. Thermal comfort in the elderly. Transactions of the American Society of Heating, Refrigerating and Air Conditioning Engineers Inc 1972;78:131-7.

${ }^{8} \mathrm{Griffiths}$ ID, McIntyre DA. The balance of radiant and air temperature for warmth in older women. Environ Res 1973;6:383-8.

- McIntyre DA. Determination of individual preferred temperatures. Transactions of the American Society of Heating, Refrigerating and Air Conditioning Engineers Inc 1975;81:131-9.

${ }^{10}$ Gagge AP, Burton AC, Bazett HC. A practical system of units for the description of the heat exchange of man with his environment. Science $1941 ; 94: 428-30$.

${ }^{11}$ Bedford T. Basic principles of ventilation and heating. London:HK Lewis, 1974:101-3.

12 Tanner WP, Swets JA. A decision-making theory of visual detection. Psychol Rev 1954;61:401-9.

(Accepted 29 October 1980)
ONE HUNDRED YEARS AGO The question asked in the House of Commons by Sir H Maxwell, on Tuesday last, may be taken as a sign of the growing interest excited in this country with regard to the artificial butters, known as "oleo-margarine," "butterine," "bosh-butter," "juene," and other names, that are now being so largely exported from America. In the United States, the battle of genuine versus artificial butter has, for some years, been raging with great fury; and, in an instructive Parliamentary paper issued by the Board of Trade last session, reports and chemical analyses appeared, side by side, demonstrating the perfect wholesomeness of oleo-margarine, and its extreme unwholesomeness. The language used by both parties was such as to render it almost impossible to form an unbiassed judgment as to the purity or otherwise of the products in question; and their wholesomeness, therefore, as articles of food, must still be regarded as a moot point. Whatever be their quality, however, the fact cannot be blinked that enormous quantities are being increasingly exported from the States for sale in this and other countries. Mr A E Bateman, one of the officials of the Board of Trade, shows, in a letter just printed as a Parliamentary paper, that, during the first nine months of 1880 , no less than $15 \frac{3}{4}$ millions of pounds of admitted oleo-margarine (to say nothing of the further amounts fraudulently shipped as genuine butter) were exported from the port of New York alone. Rotterdam took the greater part of these shipments; but Antwerp, London, Liverpool, and especially Glasgow, are also credited with very large consignments. In Holland, the oleo-margarine is mixed with milk and colouring agents, to give it a resemblance to butter; and is then churned and converted into butterine, and reshipped, chiefly to this country. There can, indeed, be no sort of doubt that a vast proportion of the cheaper butter now on sale is, to a great extent, composed of this substance; and it is significant as showing the need that is being felt for some supervision over its sale, that, in the local Bill promoted by the Town Council of Birkenhead this session, is a section (No 487) proposing to give the medical officer of health, or inspector of nuisances, the same powers of inspecting "butterine, or any preparation intended to represent butter," as with regard to unsound meat. So long as butterine is sold as such, there is, of course, no fraud on the consumer; but it seems certain that it is customarily sold as genuine butter. In that case, it will, of course, come within the provisions of the Sale of Food and Drugs Acts; and since it seems, from the published reports, that the expense of the manufacture of oleo-margarine is but little less than that of genuine butter, its sale under its right name would probably not be sufficiently remunerative in this country for it to displace butter in public estimation to any serious extent. (British Medical fournal, 1881.) 